\title{
THE EFFECTS OF HYPERBARIC EXPOSURE ON IMMEDIATE AND DELAYED CHANGES IN CORE TEMPERATURE AND ITS CIRCADIAN FLUCTUATIONS
}

\author{
Sławomir Kujawski ${ }^{1)}$, Joanna Słomko ${ }^{1)}$, Monika Zawadka-Kunikowska ${ }^{1)}$, Mariusz Kozakiewicz ${ }^{2)}$, \\ Jacek J. Klawe ${ }^{1)}$, Małgorzata Tafil-Klawe ${ }^{3)}$, Paweł Zalewski ${ }^{1)}$ \\ ${ }^{1)}$ Faculty of Hygiene, Epidemiology and Ergonomics, Department of Health Sciences, Nicolaus Copernicus in Bydgoszcz, Poland \\ 2) Department and Institute of Food Chemistry University of Nicolaus Copernicus Collegium Medicum in Bydgoszcz, Nicolaus Copernicus University in \\ Torun, Poland \\ ${ }^{3)}$ Department of Physiology, Collegium Medicum in Bydgoszcz, Nicolaus Copernicus University in Torun, Poland
}

\begin{abstract}
Changes observed in the core body temperature of divers are the result of a multifaceted response from the body to the change of the external environment. In response to repeated activities, there may be a chronic, physiological adaptation of the body's response system. This is observed in the physiology of experienced divers while diving. The purpose of this study is to determine the immediate and delayed effects of hyperbaric exposure on core temperature, as well as its circadian changes in a group of three experienced divers. During compression at 30 and 60 meters, deep body temperature values tended to increase. Subsequently, deep body temperature values showed a tendency to decrease during decompression. All differences in core temperature values obtained by the group of divers at individual time points in this study were not statistically significant.

Keywords: diving, deep core temperature, hyperbaric exposure.
\end{abstract}

ARTICLE INFO

PolHypRes 2017 Vol. 60 Issue 3 pp. 37 - 48

ISSN: $1734-7009$ eISSN: 2084-0535

Original article

DOI: $10.1515 /$ phr-2017-0013

Pages: 12 , figures: 5 , tables: 3

Submission date: $13.12 .2016 r$.

page www of the periodical: www.phr.net.pl

Acceptance for print: 03.04.2017r.

Publisher

Polish Hyperbaric Medicine and Technology Society 


\section{INTRODUCTION}

Homoeostatic regulation of core body temperature is one of the fundamental mechanisms necessary for survival; however, the term "temperature level" requires precise determination of the measurement location [1]. For example, a temperature range of 33.2$38.2^{\circ} \mathrm{C}$ was measured in the mouth cavity at the same time as $34.4-37.8^{\circ} \mathrm{C}$ was measured in the rectum; the value obtained from surface measurement in the axillary fossa was $35.5-37.0^{\circ} \mathrm{C}[2]$.

One of the methods for measurement of core body temperature is the use of a wireless telemetric system where the measurement is based on the signal emitted from a swallowed sensor. What is interesting is that the method most commonly used in studies on physical exercise is the rectal method, although changes in this indicator are delayed in relation to changes in the exercise intensity or core blood temperature; hence, this method of measurement is considered adequate only at rest $[1,3]$.

Measurements of core temperature during diving are interesting. Changes in the value of this parameter during diving may result indirectly from the consequences of mechanisms which contribute to decreased oxygen consumption in divers. Both the intense vasoconstriction of peripheral and visceral capillary beds and a reduction in oxygen consumption lead to oxygen being spared for use in priority organs, such as the brain or heart [4]. The increased blood flow in the jugular artery is consistent with the interpretation that blood flow is diverted from peripheral to cerebral circulation [5].

In a response to frequently repeated changes in the external environment, a chronic physiological adaptation of the body's reaction to that change may develop. It has been demonstrated that subjects with 7-10 years' diving experience are characterised by lower levels of blood acidity and oxidative stress in response to breathhold diving [6]. What is interesting is that the reaction to diving is not the same when the breath is not held during diving [7].

The aim of this study was to determine the effect of exposure to hyperbaric conditions on the immediate and delayed changes in core temperature and its circadian fluctuations in a group of three experienced divers.

\section{MATERIAL AND METHODS}

Three male subjects, with experience in diving (from 2 to 9 years) participated in the study. The anthropometric data of the study participants are shown in Table No. 1. During the first day of the study protocol, the subjects underwent two exposures in the hyperbaric chamber. Table No. 2 presents the timeline for the course of the study. The first exposure lasted from 12:00 p.m. to 1:00 p.m. The volunteers were placed in a hyperbaric chamber and subjected to compression of $400 \mathrm{kPa}$. The exposure plateau was ca. 30 minutes, and it was followed by a gradual decompression. The decompression pattern used following the exposure to $400 \mathrm{kPa}(0.4 \mathrm{MPa}-0.3 \mathrm{MPa}$ $+1 \mathrm{MPa}$ atmospheric pressure) was the same as that used after diving to 33 meters, which corresponds to a pressure of $440 \mathrm{kPa}$. The breathing gas used during the interventions in the hyperbaric chamber was air [8].

During the second exposure, the compression simulated a depth of 60 meters. The whole experiment lasted from 1:30 p.m. to 6:30 p.m., with a decompression time of 4 hours.

\begin{tabular}{lccccc} 
i.d. & age & height $[\mathbf{c m}]$ & weight $[\mathbf{k g}]$ & BMI & \multicolumn{2}{c}{$\begin{array}{l}\text { years of } \\
\text { diving } \\
\text { experience }\end{array}$} \\
\hline DIVE_001 & 29 & 1,90 & 92 & 25,48 & 4 \\
\hline DIVE_002 & 29 & 1,80 & 72 & 22,22 & 9 \\
\hline DIVE_003 & 31 & 1,78 & 75 & 23,67 & 2 \\
\hline
\end{tabular}

Day 1. Day of exposure to hyperbaric conditions.

10.00

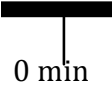

Measurement
12.00

13.0013 .30

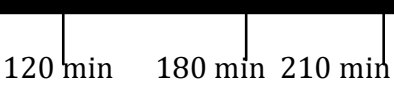

$30 \mathrm{~m} \quad 30 \mathrm{~m} \quad 60 \mathrm{~m}$

beginning end beginning
18.30

10.00
$390 \mathrm{mih} \quad 1440 \mathrm{~min}$

$60 \mathrm{~m}$

end 
Day II. Follow-up day.

10.00

10.00

$0 \min$

Measurement

beginning

Fig. 1 Intervention timeline

Core temperature measurements were conducted with the Vital Sense System from Mini Mitter, now Philips Respironics (Vital Sense, Mini Mitter Co. Inc., Bend Oregon, USA), a certified device used for the remote measurement of internal and external body temperature. This system consists of two components: a mobile monitor used for the recording, storage and export of digital data comprising measured temperature values, and a remote capsule - the Core Body Temperature Capsule (CBTC). The CBTC transmits the measured basic body temperature values in the form of a radio signal. The study subject is required to swallow the capsule with a small amount of warm water.

After ca. one minute the device can conduct the first measurement of core temperature, emitting radio signals at 15-second intervals; the mean value of four successive measurements is saved in the monitor's memory. The remote capsule is resistant to gastric enzymes and is excreted from the patient's body without any side effects or influence on the patient's gastrointestinal tract functions $[9,10]$. Advantages of this method include: a possibility of obtaining a continuous measurement of the core temperature, an option for recording circadian dynamic changes in core temperature, and repeatability and reliability of the obtained results [11]. During the first day, several minutes before 10:00 a.m., the subjects swallowed the capsules. When necessary, the subjects received another capsule to maintain continuity of the measurements. Missing data was supplemented with the mean value of the previous 3 measurements.

The results were analysed with a modified Cosinor rhythmometer. The algorithm used is based on the least squares method and fits a sinusoidal wave to the time series; next, a non-parametric analysis is conducted to verify the level of burdening of findings with a type I error by the random shuffling of time series values from the source data. The iterative method (Monte-Carlo simulation) allows the determination of the level of statistical burdening of findings with a type I error. The cosinor curve was matched according to the cosinor analysis method for the time series, as described by Nelson et al. [12]. The algorithm used is a modified version of the algorithm presented by Storch et al. [13], made available courtesy of Mr Ian David Blum [14].

The use of this type of data modelling facilitates interpretation by presenting several crucial parameters of the circadian rhythm of core temperature. The following parameters can be calculated with the method used:

M - MESOR, Midline Statistic of Rhythm, a rhythm-adjusted mean

Amp - amplitude, a half of the distance between peaks of the match curve

Phi - Acrophase, a time point in the cycle characterised by the highest amplitude (expressed in radians)

RSS - residual sum of squares, measured as a match curve deviation from the initial wave shape.

The data was analysed with the statistical package STATISTICA 13.1 (StatSoft, Tulsa, OK) and MATLAB (MATLAB and Statistics Toolbox Release 2007a, The MathWorks, Inc., Natick, Massachusetts, United States). Comparison of results obtained on Day 1 and Day 2 was done with the Wilcoxon signed-rank test.

\section{RESULTS}

Fig. 2 presents values of core temperature on Day 1, during which two exposures to hyperbaric conditions occurred. The total measurement time presented in the chart was 1440 minutes. Participant No. 1 was characterised by the highest mean value of circadian temperature. 


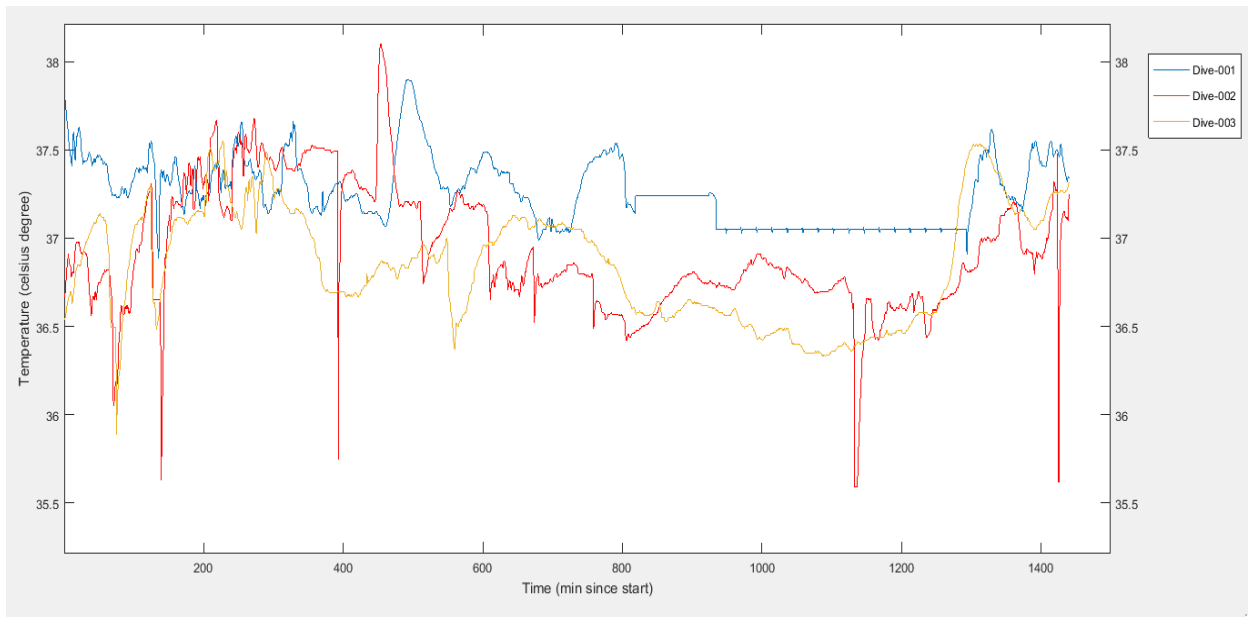

Fig. 2 Temperature values during day 1

Fig. 3 presents the time at which the participants were exposed to hyperbaric conditions simulating 30 meters depth. A slight increase in the core temperature is visible in the first minutes of exposure in all three participants before this value decreases significantly. The lowest core temperature values were noted between 11 and 18 minutes of exposure to hyperbaric conditions, then the temperature values increased; from the lowest value to the end of the exposure they are characterised by significant variability.

Fig. 4 shows changes in core temperature values during the hyperbaric exposure simulating 60 meters depth. Changes in the temperature values were slower than during exposure to 30 meters depth.

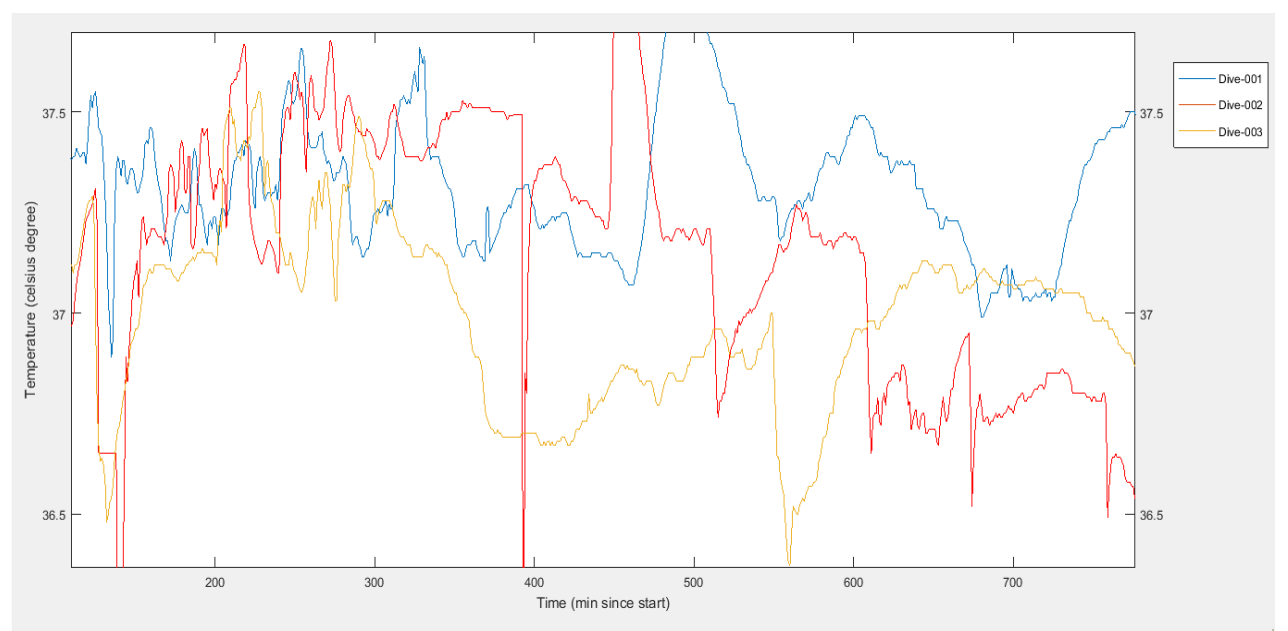

Fig. 3 Temperature values during hyperbaric conditions at 30 meters.

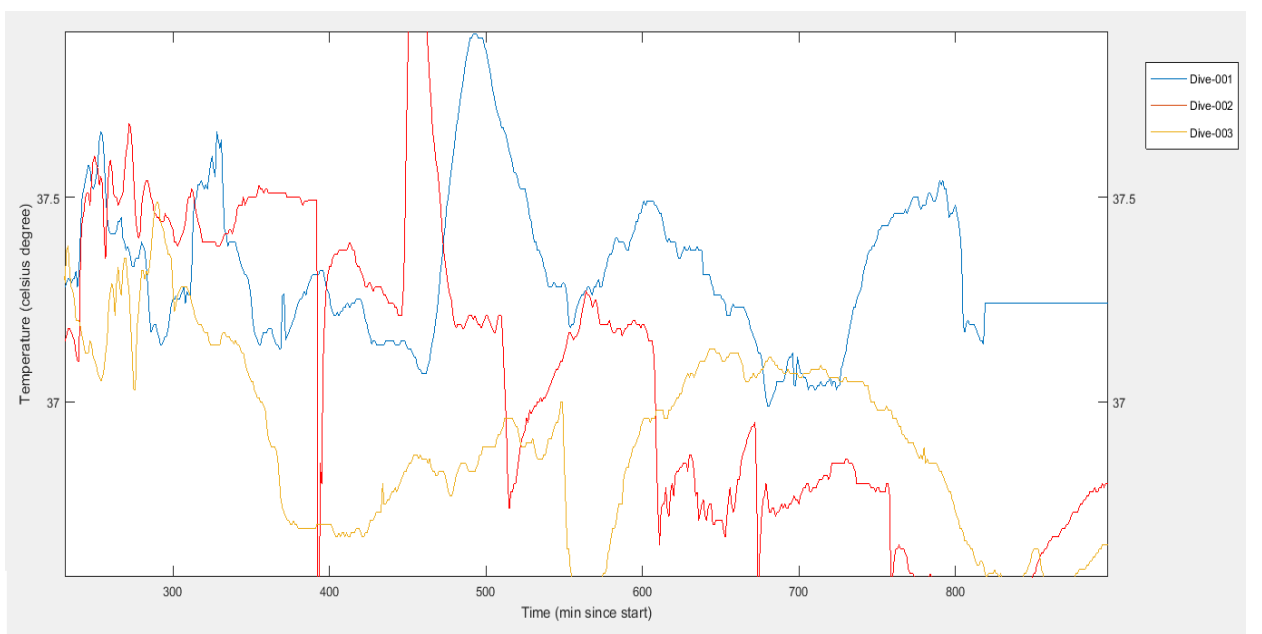

Fig. 4 Temperature values during hyperbaric conditions at 60 meters. 
Fig. 5 presents the changes in core temperature during the second day, during which the subjects were not subject to any intervention. Fig. 4 shows a clearer difference, versus Fig. 2, between mean core temperature values of the subjects during the second part of the day
(10:00 p.m. to 10:00 a.m., corresponding to $720-1440$ minutes of measurement): these values were lower in all three subjects than during the first part of the day.

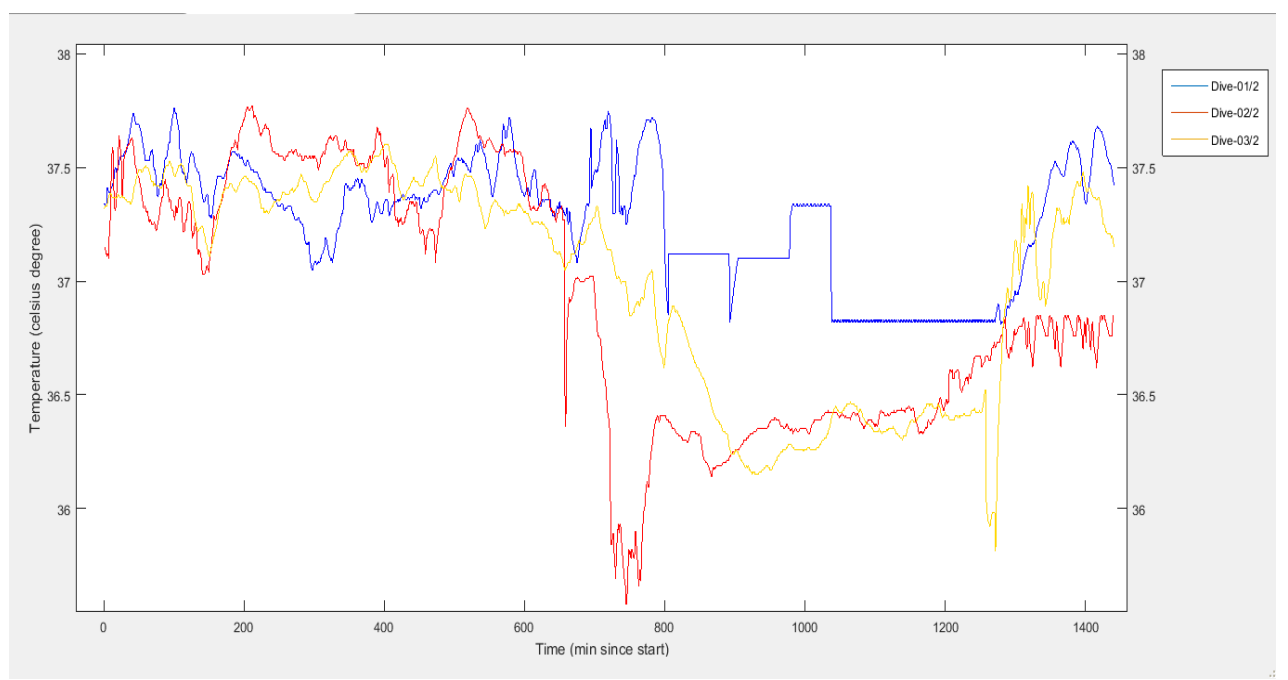

Fig. 5 Temperature values during follow-up day.

Table No. 2 shows the results from the analysis with the cosinor method for each subject from Day 1, during which exposure to hyperbaric conditions occurred, and Day 2. The Wilcoxon signed-rank test showed that the difference in these values in the subjects between Day 1 and Day 2 was not statistically significant ( $p>0.05$ ).

Results of the cosinor analysis for individual patients.

\begin{tabular}{lllllll}
\hline & Dive_01 & Dive_02 & Dive_03 & Dive_01/2 & Dive_02/2 & Dive_03/2 \\
\hline M & 37.26 & 36.93 & 36.85 & 37.27 & 36.92 & 36.99 \\
\hline Amp & 0.13 & 0.35 & 0.26 & 0.23 & 0.68 & 0.61 \\
\hline phi & -1.42 & -1.43 & -1.08 & -1.61 & -1.28 & -1.35 \\
\hline RSS & 36.29 & 89.11 & 97.32 & 64.07 & 88.84 & 57.40 \\
\hline
\end{tabular}

Table No. 3 presents values from the analysis with the cosinor method for the whole group $(n=3)$ of subjects. The core temperature values were characterised by a higher average cycle value during Day 2 , during which the subjects were not subjected to any intervention Amplitude values and the residual sum of the squares were lower during Day 2. The acrophase value shows that the time interval during which the highest temperature values were noted differed between Day 1 and Day 2; however, these differences were not statistically significant $(p>0.05)$.

Results of the cosinor analysis for whole group.

\begin{tabular}{|c|c|c|}
\hline variable & I day & II day \\
\hline MESOR & 37.2612 & 37.2729 \\
\hline Amplitude & 0.139085 & 0.234665 \\
\hline Acrophaze & -1.42005 & -1.6121 \\
\hline RSS & 36.2916 & 64.075 \\
\hline
\end{tabular}


Table No. 4 shows the core temperature values for individual subjects: the maximum and minimum obtained values and the mean value at each time point during Day 1 . As can be seen, this method does not fully show the dynamics of the changes in the measured value: only in the first patient did the lowest value occur during the exposure to hyperbaric conditions (at 14 minutes of diving to 30 meters). Furthermore, the results of the first exposure do not show an initial slight increase in temperature. The results show that 15 minutes after entrance into the chamber, the core temperature value dropped in all subjects, with the lowest value recorded for subject No. 2. The maximum value occurred at 6:11 p.m. in subject No. 1, at 5:36 p.m. in subject No. 2 and at 1:46 p.m. in subject No. 3 .

Tab. 4

Core temperature measurements at selected time points on day I.

\begin{tabular}{llllllllllll}
\hline & $\min$ & $\max$ & 12.00 & 12.15 & 13.00 & 13.30 & $\begin{array}{l}14.30- \\
15.00\end{array}$ & 16.30 & 17.30 & 18.30 & 19.00 \\
\hline Dive_01 & 36,89 & 37,9 & 37,37 & 36,89 & 37,26 & 37,49 & 37,05 & 37,35 & 37,37 & 37,54 & 37,28 \\
\hline Dive_02 & 35,59 & 38,1 & 37,26 & 33,88 & 37,39 & 37,58 & 37,38 & 37,31 & 38,09 & 36,95 & 37,06 \\
\hline Dive_03 & 35,81 & 37,55 & 37,28 & 36,48 & 37,11 & 37,47 & 37,03 & 36,69 & 36,85 & 36,94 & 36,91 \\
\hline Average & 36,09 & 37,85 & 37,30 & 35,75 & 37,25 & 37,51 & 37,15 & 37,12 & 37,44 & 37,14 & 37,08 \\
\hline
\end{tabular}

\section{DiscuSSION}

The number of studies analysing values from only one selected time of day, or from two individual points in time separated by 12 hours, still remains too high [15]. This method cannot fully reflect the dynamics of the changes in the measured parameters throughout the circadian cycle; in particular, when there is continuous measurement characterised by a significant time density, or when two points in time included in the analysis are selected at the maximum or minimum of a determined curve [15].

One of the limitations in this study is the lack of measurement of a subjectively perceived temperature. In the study's subjects, a change in the ambient temperature lead first to a change in the subjectively perceived temperature and only later to a change in the temperature measured at the skin's surface [16]. A study on the changes in subjectively perceived temperature and core temperature in divers during exposure to hyperbaric conditions would be interesting.

Core temperature values in divers, exposed to hyperbaric conditions simulating 30 meter and 60 meter depth changes, fluctuated similarly to the temperatures of gases subjected to compression and adiabatic expansion: during compression, the gas (in this case air) temperature increases, while during adiabatic expansion the temperature value decreases [17].
During the exposure of 60 meters, a significant venous return of blood, squeezed out of skin vessels and characterised by lower temperature, results in the reduction of core temperature.

Why was there such a rapid decrease in temperature during the exposure at 30 meters? Why was the situation different at 60 meters? Was it associated with the speed of compression or with some other factor? Why was there a sudden increase in the temperature during the first stage of compression at 30 meters, followed by a decrease?

\section{Conclusions}

All differences in noted core temperature values obtained for the group of divers $(n=3)$ at individual time points in this study were statistically insignificant. During the compression at 30 meters and 60 meters alike, the core temperature values tended to increase. The core temperature values in divers during decompression tended to decrease. In the case of exposure to hyperbaric conditions simulating 60 metres depth, changes in core temperature values were milder than in the case of 30 meters. Furthermore, in the 60 metres condition, the speed of compression and decompression was also lower than in the 30 metres case.

\section{REFERENCES}

1. Brengelmann GL. Dilemma of body temperature measurement. Man in Stressful Environments, Shiraki K, Yousef MK. Springfield, IL: CC Thomas Publishers. 1987 5-22

2. Sund-Levander M, Forsberg C, Wahren LK. Normal oral, rectal, tympanic and axillary body temperature in adult men and women: a systematic literature review. Scand J Caring Sci. 2002 Jun;16(2):122-8;

3. Blatteis CM. Methods of body temperature measurement. Physiology and pathophysiology of temperature regulation. River Edge, NJ: World Scientific Publishing. 1998 273-9;

4. Elsner R, Gooden B. Diving and asphyxia. A comparative study of animals and man. Monogr Physiol Soc. 1983:40:1-168;

5. Pan AW, He J, Kinouchi Y, Yamaguchi H., Miyamoto H. Blood flow in the carotid artery during breath-holding in relation to diving bradycardia. Eur J Appl Physiol Occup Physiol. 1997;75(5):388-95. DOI:10.1007/s004210050177;

6. Joulia F, Steinberg JG, Wolff F, Gavarry O, Jammes Y. Reduced oxidative stress and blood lactic acidosis in trained breath-hold human divers Respir Physiol Neurobiol. 2002 Oct 23:133(1-2):121-30;

7. Andersson J, Schagatay E, Gislén A, Holm B. Cardiovascular responses to cold-water immersions of the forearm and face, and their relationship to apnoea Respir Physiol Neurobiol. 2002 Oct 23;133(1-2):121-30;

8. Słomko J, Kozakiewicz M, Klawe JJ, Tafil-Klawe M, Siermontowski P, Zalewski P. Circadian Rhythm of Core Body Temperature (Part II): Hyperbaric Environment Influence on Circadian Rhythm of Core Body Temperature. Polish Hyperbaric Research. 2016 Dec 1;57(4):19-25. DOI: $10.1515 / \mathrm{phr}-2016-0022$

9. McKenzie JE, Osgood DW. Validation of a new telemetric core temperature monitor. J Therm Biol. 2004, 29(7), 605-611;

10. Zalewski P, Klawe JJ, Buszko K, Tafil-Klawe M, Łukowicz M. Daily measurement of internal and external body temperature with the use of Journal of Polish Hyperbaric Medicine and Technology Society 
VitalSense system. Acta Bio-Optica et Informatica Medica, 2008, 2, 14

11. Byrne C, Lim CL. The ingestible telemetric body core temperature sensor: a review of validity and exercise applications. Br J Sports Med. 2007 Mar;41(3):126-33. Epub 2006 Dec 18. DOI:10.1136/bjsm.2006.026344;

12. Nelson W, Tong YL, Lee JK, Halberg F. Methods for cosinor-rhythmometry. Chronobiologia, 1979, 6(4), 305

13. Storch KF, Paz C, Signorovitch J, Raviola E, Pawlyk B, Li T, Weitz CJ. Intrinsic circadian clock of the mammalian retina: importance for retinal processing of visual information. Cell, 2007, 130(4), 730-741.

14. Ian David Blum. Cosinor-FDR. https://github.com/storchlab, 2014;

15. Cornelissen G. Cosinor-based rhythmometry. Theor Biol Med Model. 2014 Apr 11;11:16. doi: 10.1186/1742-4682-11-16. doi: 10.1186/17424682-11-16;

16. Xiong J, Lian Z, Zhou, X, You J, Lin Y. Effects of temperature steps on human health and thermal comfort. Building and Environment, 2015, 94, 144-154;

17. Moran MJ. Engineering thermodynamics. In The CRC Handbook of Mechanical Engineering, Second Edition. 2004, CRC Press, 271.

dr hab. n. o zdr. dr n. med. Paweł Zalewski

Katedra Higieny, Epidemiologii i Ergonomii,

Wydział Nauk o Zdrowiu, Collegium Medicum UMK w Bydgoszczy

ul. M. Curie Skłodowskiej 9

85-094 Bydgoszcz

p.zalewski@cm.umk.pl 